\title{
Redesigning an Appropriate Technology Shredder for Manufacture in a Developing Country
}

\author{
Jeffrey Weiss \\ Graduate Student, School of Engineering \\ University of St. Thomas \\ St. Paul, MN 55105 \\ jpweiss@stthomas.edu \\ Camille George \\ Assistant Professor, School of Engineering \\ University of St. Thomas \\ St. Paul, MN 55105 \\ cmgeorge@stthomas.edu \\ John Walker \\ 3M Fellow, School of Engineering \\ University of St. Thomas \\ St. Paul, MN 55105 \\ jwalker@stthomas.edu
}

Abstract - The principles of Design for Manufacturing and Assembly (DFMA) were applied to the redesign of a manual shredding machine used to harvest breadfruit in the Republic of Haiti. The DFMA methodology examined each function of the shredder assembly to determine if a part could be eliminated or combined with another part and if there were simpler ways to meet the performance criteria without sacrificing quality. A breadfruit shredder designed by a previous senior design group that met the customer and engineering specifications was subjected to the DFMA process resulting in a machine that was easier to build in a developing country, used materials that were more commonly available, had a reduced number of parts, was more robust, was easier to clean and keep sanitary, and cost less to make.

Index Terms - appropriate technology, manual shredding, manufacturing in developing countries

\section{INTRODUCTION}

This paper focuses on redesigning for manufacture a manual breadfruit shredder for the Republic of Haiti. As one of the poorest nations in the Western hemisphere, Haiti is a country that lacks a stable government, education system, manufacturing base, or infrastructure. Malnutrition is a problem to the extent that the US Department of State estimated that the child malnutrition rate was 22 percent in 2000. ${ }^{\mathrm{i}}$ Breadfruit is a natural food resource that is underutilized because it rots quickly and is currently not being stored. Drying breadfruit can extend its shelf life and this process is best done when the shreds are even and consistent. A simple manual shredder was developed to produce consistent shreds for the inhabitants of Haiti by a group of senior engineering students at the University of St. Thomas (UST) in conjunction with Compatible Technology International (CTI), an international non-profit organization. The student version of the shredder was designed and tested and found to meet all of the criteria that they had established. Despite meeting the requirements, the machine had the potential to be optimized to 
better reflect the manufacturing capabilities available in a developing country. This paper details the redesign work to make this shredder more suitable for the Haitians by making it easier to manufacture while reducing its cost.

\section{The Haitian Situation}

Haiti is considered to be the poorest and most destitute country in the Western hemisphere. ${ }^{\text {ii }} \mathrm{A}$ majority of its population lives in poverty and relies on subsistence farming for survival. A summary of human index statistics is presented in Table I. It has a long history of political upheaval and unrest since it gained its independence from France in 1804. The rotation of various governments and civil wars has hindered investment in the country and led to high unemployment and dismal living conditions for its inhabitants. The education system is broken or non-existent and there has been an exodus of knowledge from the island as people flee the dire conditions and turmoil.

TABLE I

HAITI FACTS iii

\begin{tabular}{|c|c|}
\hline Population (Estimate, 2004): & $8,121,622$ \\
\hline Land Area: & $27,750 \mathrm{sq} \mathrm{km}$ \\
\hline Average Life Expectancy: & 53 years \\
\hline Population Below Poverty Line: & $80 \%$ \\
\hline Percentage of Population in Agriculture: & $66 \%$ \\
\hline Unemployment Rate (no formal job): & $66 \%$ \\
\hline Average Literacy Rate: & $52 \%$ \\
\hline
\end{tabular}

Most of the original Haitian forests have been cut down for fuel and the desire to cultivate more land. This deforestation has resulted in massive land erosion in the mountainous country and a net loss of arable land. ${ }^{\text {iv }}$ Breadfruit trees are abundant throughout the island and are one of the few trees that have survived the deforestation process.

\section{Breadfruit}

Breadfruit is an important food source and has become a staple of the diet for the inhabitants of islands in the Caribbean Sea (Figure 1). It has some nutritional value and high starch content. ${ }^{\mathrm{v}}$ Typical ways of preparing breadfruit are grilling, roasting, adding it to soups, and mashing.

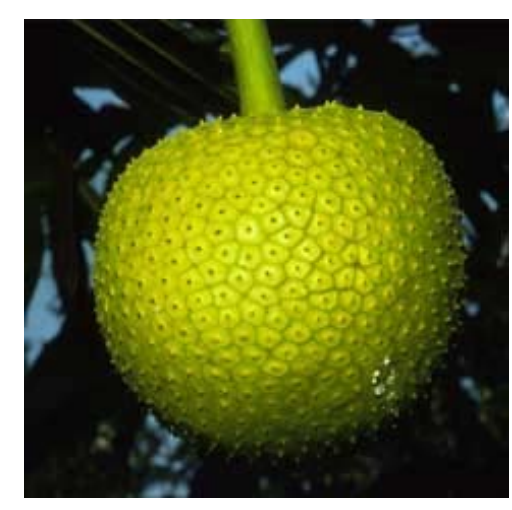

FIGURE 1

FRUIT OF THE BREADFRUIT TREE 
One of the unique properties of breadfruit is its limited shelf life. Once it ripens and comes off of the tree, it will last between one and three days. ${ }^{\mathrm{vi}}$ Breadfruit trees produce fruit twice a year for about three-weeks (six weeks per year). Much of the fruit rots on the ground because of the inability to consume it all during the short time that it is in season. ${ }^{\text {vii }}$ Standard preservation methods for fruit, such as canning, are not common in Haiti and will increase the price for the food. Therefore, there was a need to develop a more economical way of preserving the breadfruit needed to be developed to utilize its potential to alleviate long-term hunger on the island.

\section{The Tommy Shredder}

The development of a breadfruit harvesting process was taken on by two groups of senior mechanical engineering students at the University of St. Thomas in St. Paul, Minnesota in the 2003-2004 academic year. The first team attempted to devise a solar drier to quickly dehydrate the shredded breadfruit. The drying project showed that the shredded fruit could be successfully air-dried with an optimal size of the shred of $1 / 2$ " wide. ${ }^{\text {viii }}$ The dried product can be stored for up to a year. ix $^{\text {in }}$

The second team developed a small, economical shredder that could efficiently and quickly process the breadfruit down into shreds so that it could be dried. ${ }^{\mathrm{x}}$ The purpose of the original project was to "find the most efficient means of mechanically shredding breadfruit to best prepare the fruit for the drying process." The “Tommy Shredder" developed by the student senior design team produced an average shred rate of 200 pounds/hour and cost less than US\$100 to build. This shredder became the baseline for the current project and is shown in Figure 2. Due to civil unrest in Haiti in the spring of 2004, the students traveled to St. Vincent to test the shredder with fresh breadfruit and to obtain user input on the shredder design. User input was solicited from various small producers: bakers, hot sauce makers, and a women's farming cooperative. Manufacturing input was solicited from local fabrication shops and the St. Vincent Technical School. The user input was invaluable and had a constructive impact on the durability and flexibility of the design. Details of the concept and design methodology, and the testing and validation process can be found in their final report. ${ }^{\mathrm{x}}$ 


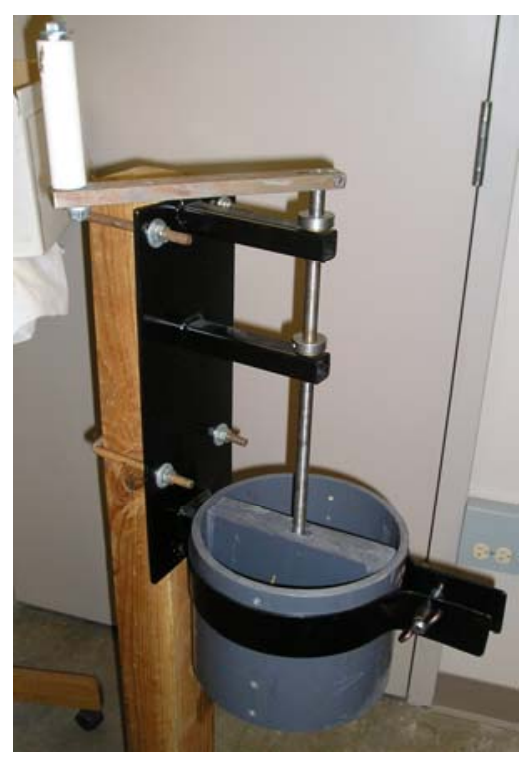

FIGURE 2

The TOMmy SHREDDER AS DONE BY THE SENIOR DESIGN TEAm 2004

The target beneficiaries of the shredder are women's farming cooperative groups based in Haiti. CTI, whose mission is to bring appropriate technologies to help increase food supplies and storage capacities in the developing world, has been working with the Methodist Church missions in Haiti on preserving breadfruit. Dried breadfruit can be ground into flour and local CTI volunteers have created several recipes using this breadfruit flour as the bulk material. The goal of the joint project is to create a shredder that is simple enough to use and economical enough to manufacture so that local versions could be bought with micro-loans managed by the Methodist Church of Haiti. CTI also plans on helping set up a program to buy the shredded/ground breadfruit and process it into a cereal for Haitian school children. ${ }^{\text {xi }}$ The idea is to take a resource, preserve it and add value, and then process it to create a commercial good. The objective of the undertaking is to create a way to enable farming cooperatives to generate income from a readily available raw material. The final manufacturing, integration, and support for the shredder in Haiti are to be done in its initial stages by the Committee on Development of the Methodist Church of Haiti. A plan is in place to introduce breadfruit breakfast cereal into the Methodist school system which serves $\sim 170,000$ children. The introduction of new foodstuffs is typically challenging and subject to many barriers. Currently there is no commercial market for dried breadfruit. The Methodist school system will buy the dried breadfruit directly to make and then serve a nutritious breakfast cereal. Volunteers from CTI and General Mills have taste tested several recipes with Haitian school children. The recipes use local ingredients: breadfruit, molasses, sugar, sweet potato and red beans, plus add an imported vitamin supplement. It is hoped that introduction of the wholesome cereal into the society through children rather than adults will be successful. Implementation will be coordinated across 13 pilot sites, with plans of expanding to the entire Methodist school system within five years. Members of the Catholic and Baptist mission school systems are also interested in trying the healthy breadfruit breakfast cereal. 


\section{Project OBjectives}

The current paper examined the original design and developed ways to improve it so that it would be simpler to manufacture in a developing country. A thorough literature search yielded few papers addressing the issue of constructing a simple shredding machine for manufacture and use in a developing country. Authors have discussed the importance of developing undervalued resources as an important strategy to reduce dependence on foreign imports, ${ }^{\text {xii }}$ and the importance of working within the culture of a developing country to ensure technology acceptance. $^{\text {xiii, xiv }}$ Other articles have emphasized that women in developing countries spend more time working in agriculture than men and the tasks given to them are more monotonous and tedious $^{\mathrm{xV}}$ suggesting that their labor is undervalued; and many developing countries underutilize their vast manpower resources. ${ }^{\mathrm{xvi}}$

No articles were found which directly applied the Design for Manufacturing and Assembly (DFMA) guidelines to optimize a machine design that could be made by people in a resource limited environment. The following objectives were established for the redesign of the shredder:

- $\quad$ Reduce the part count.

- Use materials and methods that would make it easier to manufacture in a developing country.

- $\quad$ Reduce the final cost of the equipment.

- Make it easier for the user to operate, clean, and repair.

Figure 3 shows an exploded view of the original Tommy Shredder identifying the following subassemblies, to which the DFMA methodology was applied: handle/ drive shaft, drive shaft bearings, frame plate, center divider, feeder tube, blade mount, and shredder blade. 


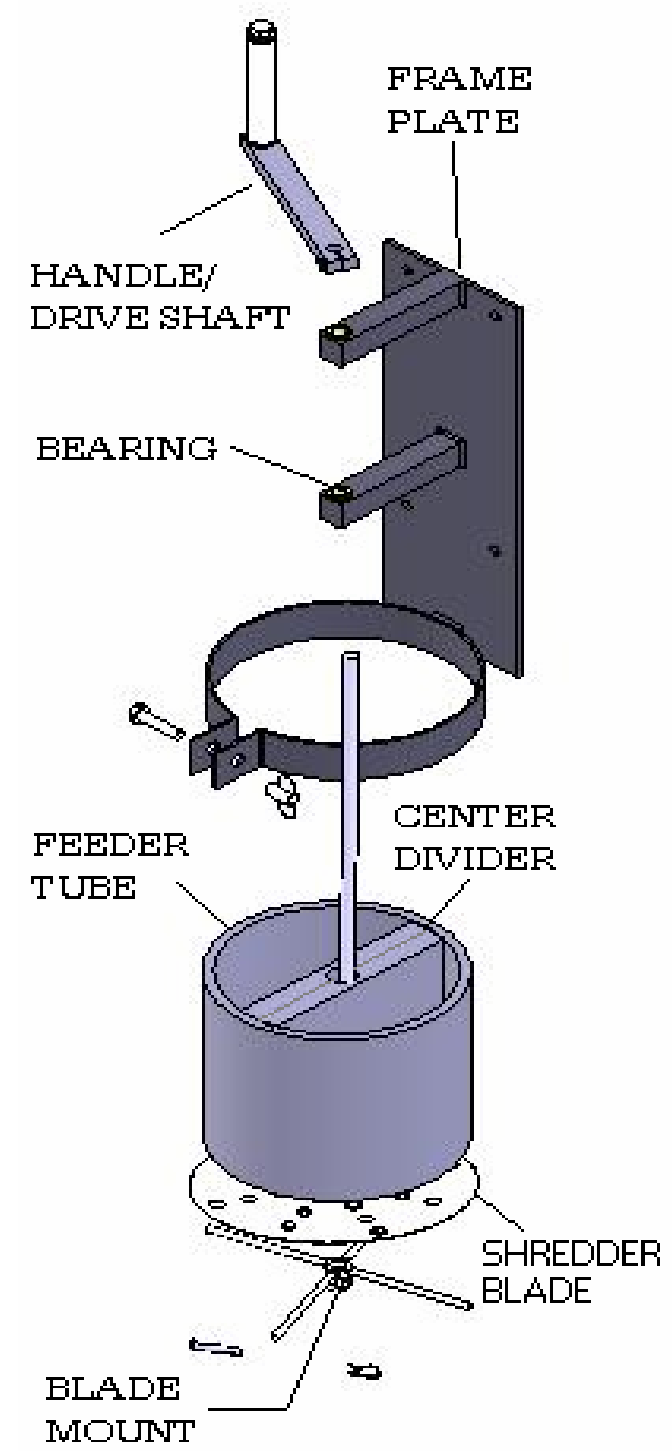

FIGURE 3

EXPLODED VIEW OF THE ORIGINAL TOMMY SHREDDER

\section{DFMA methodology}

The DFMA methodology examines each function of an assembly to determine if it can be eliminated or combined with another part and if there are simpler ways to meet the performance criteria without sacrificing quality. In general when an assembly has been subjected to the DFMA process it results in a simpler, better quality, lower cost and more reliable product.

The process of going through the methodology focuses the analysis on the existing design/build sequence and bill of materials. In essence two analyses are carried out. The first analysis generates a design that envisages an ideal assembly. All fasteners are designated to be eliminated, any process that could simplify the assembly is incorporated, and the minimum-parts guidelines are applied to all components (relationship of two adjacent parts of an assembly). 
Three questions must be asked of each part in order to reduce the part count:

- Does the part move relative to other parts already assembled?

- Must the part be of a different material or isolated from other parts in the assembly?

- Does the part need to be separate from others for assembly and disassembly purposes?

If the answer to all these three questions are 'no' then the two parts should be combined into one.

On completion of this 'ideal' analysis a second analysis is carried out. This analysis reviews the first analysis with the reality of the actual situation that will exist for the manufacture of the assembly: quantity, rate of production, funding available, environment, material availability, and economics.

- What is the cost of each material piece used? Will an alternative material work equally well while reducing cost?

- What is the availability of each different material? Is it realistically available in a developing country?

- For welded parts, will it be easy to use fixtures so that the parts can be made accurately and repeatedly.

- Is there commonality of parts? Can parts with similar functions be made to work in multiple places?

- Is there excess material on a part? Is it needed?

This results is an optimized design that fits the situation for the envisaged production of the assembly. It does not mean that all the suggested improvements are adopted (such as elimination of all fasteners), but it does represent the best situation at the time of the analysis. This would include changing the orientation of the parts to ease fabrication, making parts self-aligning, and reducing processing steps. The end state for the breadfruit shredder was to have all of the parts made on equipment typically found in a small machine shop, such as a drill, saw, welder, and lathe. The analysis of the breadfruit machine followed the above guidelines, but formal analysis sheets were not generated. The result of the analysis was incorporated directly into part sketches and proven by making iterations of actual hardware to build a prototype machine.

\section{Manufacturing in Haiti}

Little has been published on manufacturing for the developing world. Interviews with experienced personnel identified the following key points: ${ }^{\text {viii, xviii }}$

- Manufacturers in developing countries do not necessarily build things to print. Everything is custom and will look similar to what is desired, but is not quite the same.

- Creativity is not rewarded in many cultures and there is a desire to continue doing things the old way.

- Expectations in quality and standards will probably not be met. Production is not to the same quality as is found in the United States.

- There are cultural norms and practices that will be slow to change and may not be overcome.

- Women tend to not use machines, thus the design must be easy to use and relatively tool free.

Making the shredder easier to operate, clean, and repair will benefit the end user by increasing their satisfaction with the machine and making a more robust design. It will also 
reduce some of the health concerns associated with unsanitary food processing equipment. An effort was made to utilize typical design practices of the food equipment industry. This involved eliminating recessed pockets that could hold food particles ${ }^{\mathrm{xix}}$ and using durable materials that do not migrate into the food. ${ }^{\mathrm{Xx}}$ Making the machine easy to disassemble and clean will greatly increase the chances that the user will do this. User comments during the design reviews and machine testing helped identify several of the problem areas relating to cleaning.

\section{FINDINGS AND RESULTS}

The process of redesigning and modifying the breadfruit shredder involved several different iterations with all major components being modified. All of the parts for the shredder were fabricated using hand tools and simple machine tools. This generated excellent feedback about what worked well and what did not. It also gave an insight into the quality that could be expected using these tools. It should be noted that some of the design modifications resulted in more parts being used. An example of this would be the shredder blade mount and the shaft bearing blocks. The increase in parts is justified by the fact that some of the old parts may not be readily available in a developing country as was the case with the oil-impregnated bushings holding the shaft. The shredder blade mount design added parts and material but greatly increased the strength and stability of the assembly.

The pictures documenting the changes show the senior design team version on the left and the updated version on the right.

\section{Handle/Drive Shaft}

The existing handle assembly consisted of nine parts and some time consuming machining to create the clamping arrangement on the upper handle piece. The redesigning of the handle used DFMA principles to reduce the part count from nine to four and the only machining necessary was a simple hole and some welding (Figure 4). Instead of attempting to clamp the handle to the drive shaft, a single piece of steel shafting was bent into a one-piece handle assembly. The bending of the shaft was easily done by heating with a torch and bending in a vise. A welded-on washer replaced the upper clamp collar and another washer was welded below the handle to support the plastic. A piece of plastic tube is slipped over the top part of the handle for rotational purposes. It was determined that the lower clamp collar was not needed and that the plastic handle did not need to be retained from the top. 

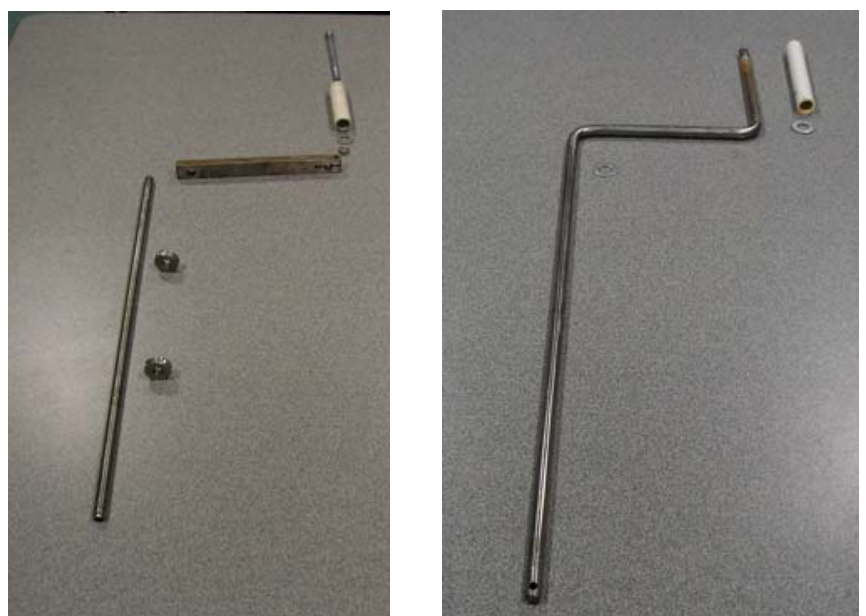

\section{FIGURE 4}

\section{Handle/Drive Shaft: Changes Showing the One Piece -Shaft And Reduced Part Count}

\section{Drive Shaft Bearings}

The previous design used an oil-impregnated sintered bronze bushing to retain the drive shaft and provide for easy turning. The bronze bushings may not be readily available in a developing country and will also slowly degrade, dropping bronze particles into the food. This was redesigned to be a round piece of nylon with two holes drilled through it (Figure 5). One hole is for a bolt to hold it onto the frame plate and the drive shaft is inserted through the other hole. The part is symmetrical so that when the drive shaft begins to wallow out its hole, the part can be flipped around and the holes switched. This will give twice the life out of the same piece. Wood or another plastic material could be used for the bearing if nylon is not available.

During fabrication it was found that inline holes were easier and more accurate to machine. The posts on the frame plate that mounted the bearings were rotated to correspond to this direction. This had the added advantage of making the posts easy to align with a shaft before they were welded (Figure 6).

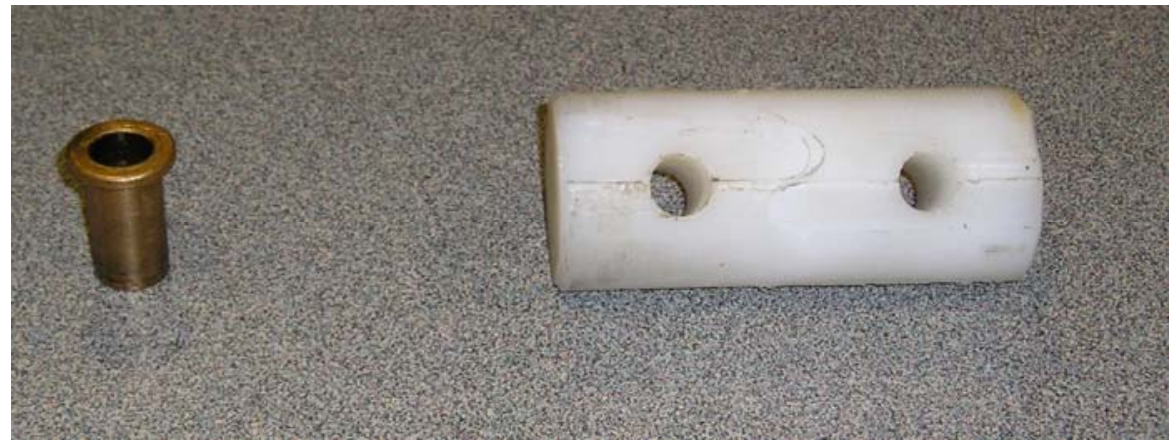

FIGURE 5

Drive SHAFT BEARING: CHANGE FROM BRONZE Bushing TO NYLON 


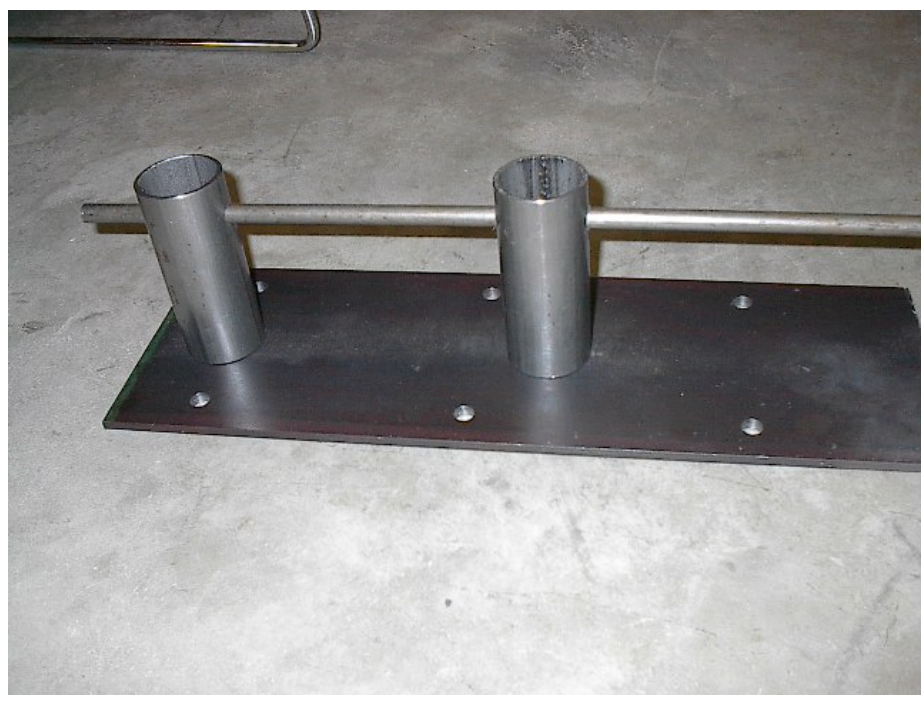

FIGURE 6

Simple Alignment of BeAring Supports on the Frame Plate fOR Welding

\section{Frame Plate}

The mount for the bearing had to be redesigned to hold the nylon bearings (Figure 7). A round piece of tube was used in place of the square tube and the nylon bearing was slipped into one end of it. A saw-cut slit was put into the end of the tube along with a bolthole. This way the bolt could be tightened and cause the tube to clamp onto the nylon bearing. The spacing of the bearings was increased so that they would support the drive shaft better. The spacer for the hoop was made from a piece of flat steel. This was changed to a piece of the same round tubing that mount the bearings. This reduced the number of different types of steel that would be needed.

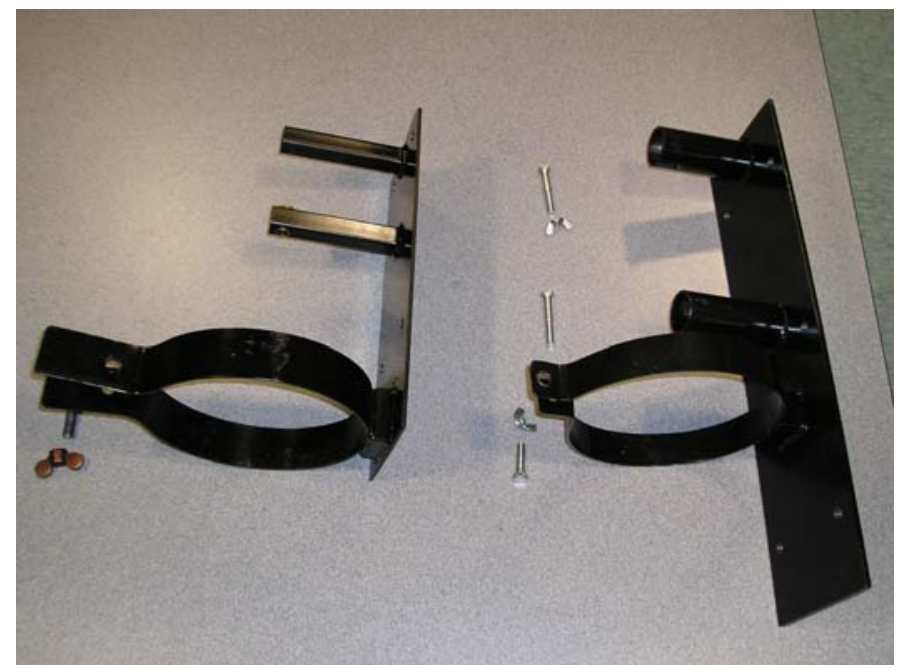

FIGURE 7

Frame Plate: Changes Showing Updated Drive Shaft Bearing Posts 


\section{Center Divider}

The center divider was two pieces of flat poly-vinyl chloride (PVC) plastic plate that were glued together and screwed inside of the feeder tube. The flat PVC was difficult to get even in the United States and the attachment method left large cracks and gaps between the inside of the barrel and the divider. The divider was not removable, so these cracks could collect food and bacteria. This divider was remade to be removable so that it could be cleaned easily. A piece of sheet steel was used instead of the flat PVC (Figure 8). This sheet steel fit between four dowel pins protruding into the inside of the feeder tube and the top fit into slots cut into the top of the feeder tube. This secured the divider on both the top and the bottom and made the divider easy to remove by pulling it out through the top. The divider and feeder tube could then be washed separately.

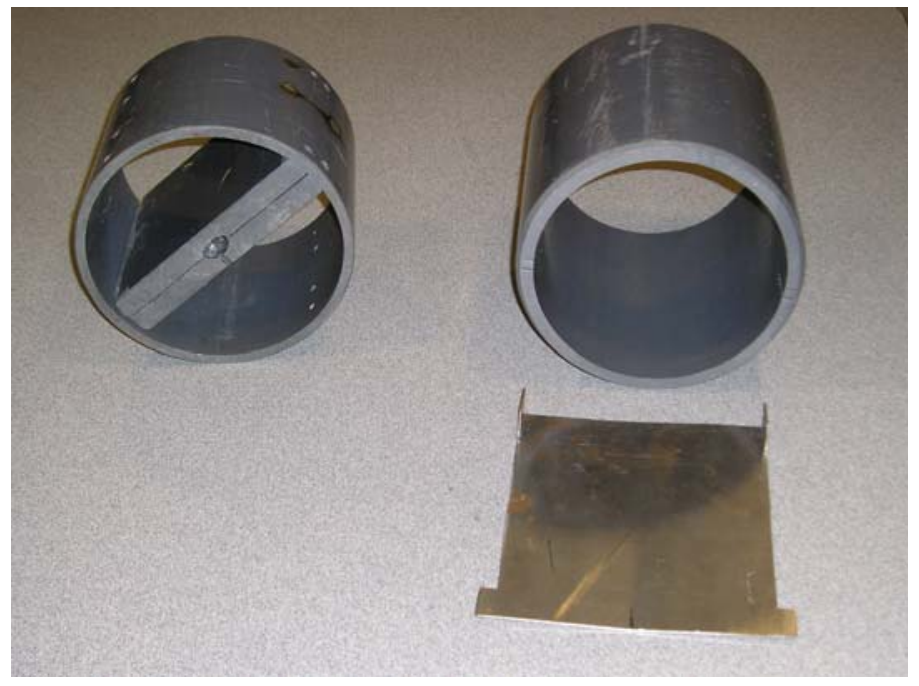

FIGURE 8

New Design has a ReMOVABle CENTER Divider

\section{Feeder Tube}

The feeder tube is round because it is easy to clamp and the shape makes the most sense with its interaction with the rotating shredder blade. If round PVC tube would not be available in certain areas, an alternative would be to use a square or octagonal box made out of wood or sheet metal. This would not be as efficient, but would work and is easy to build. The center divider could also be made out of wood if sheet metal is not available. This has the potential to trap bacteria but is an option.

\section{Blade Mount}

One of the hardest pieces to fabricate on the previous design was the blade mount. The design was also weak and it did not hold the blade flat. The mount was redesigned using a support ring that was the same size as the blade (Figure 9). All of the mounting slots on the blade could then be used so that it would lay flat and retain its shape better. The principles for assembly were used so that the assembly could be easily fixtured and welded. The center boss for mounting to the drive shaft was made to be square instead of round. It was much easier to weld on the support arms to a flat edge as compared to a round hub. The support arms were also changed from round shaft to rectangular bars. The end result was a blade mount that was much easier to 
manufacture and did a better job of supporting the blade. The new design used more material, but it is felt that this was an acceptable tradeoff for the reduced fabrication time and better support provided by the new design.

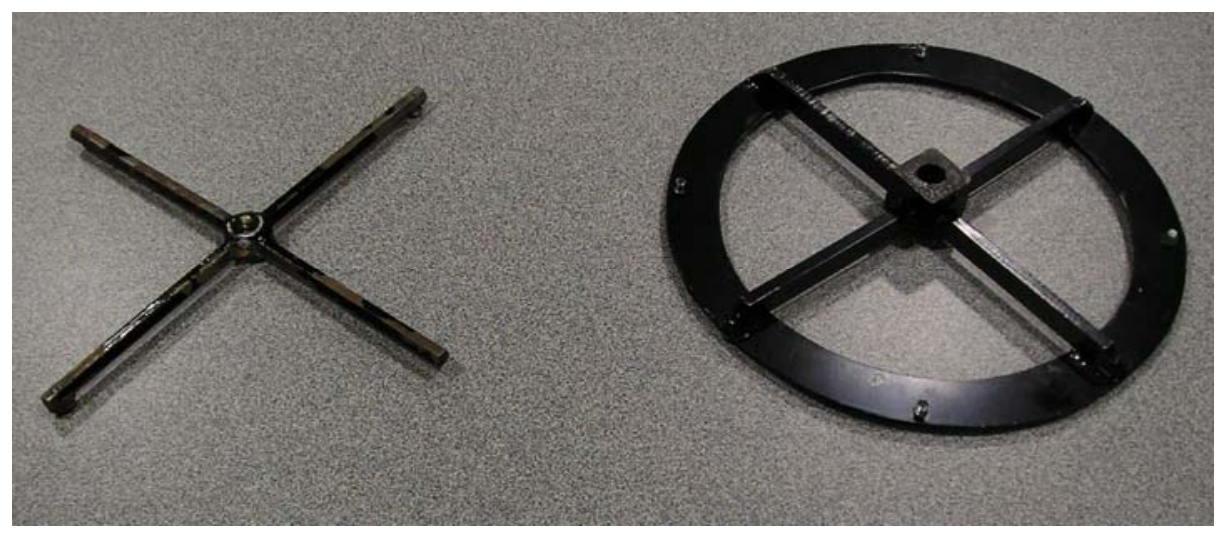

FIGURE 9

Blade Mount Changes Showing Sturdier New Design

\section{Shredder Blade}

The shredder blade is the most expensive part of the breadfruit shredder and the one that would be hardest to obtain in a developing country. The specified blade was a stainless steel commercial blade made by Hobart Company and the cost of US $\$ 27$ makes up about a third of the total cost of the shredder. The senior design team had used this blade because it fit their application and was available. A search for another blade did not lead to any compatible replacements that would be as strong and significantly reduce the cost.

The option of creating a blade for the shredder was explored as a way to reduce the cost of the machine. It was determined that if a punch and die assembly could be devised for manufacturing the blade; a fabrication shop could make their own blades. The punch and die assembly would not need to have the exact same cutting profile as the Hobart blade but one requirement was that any fabricated blade must be interchangeable with the mounting holes on a Hobart blade. This would give the end-user the option of using either one.

A manual milling machine, lathe, and grinder were used to create a simple four-row die and a matching punch (Figure 10). 


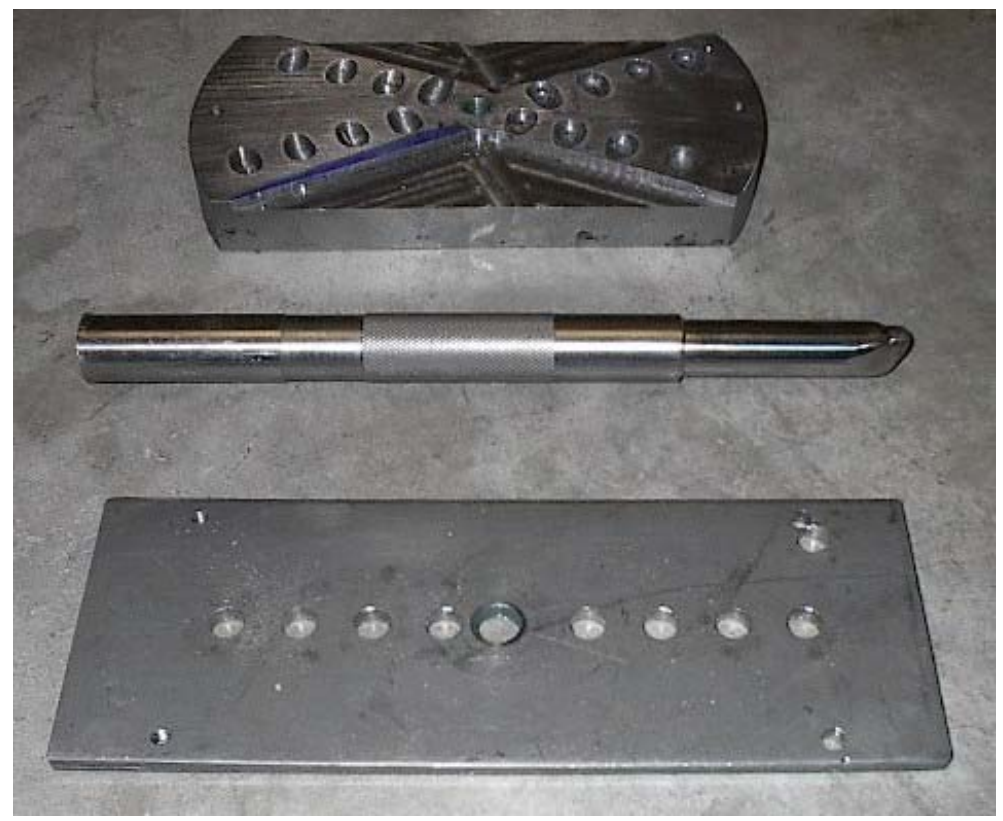

FIGURE 10

ShredDer Blade Die, Punch, and Hole Template

The punch and die was tested and found to work well. Table II shows the average results of testing using three different holes sizes and metal thicknesses. The height value is the distance that the sheet metal was deformed by the die. From the testing, it was found that the $0.438(7 / 16)$ inch diameter hole provided the best looking profile that most closely matched the Hobart blade. A material thickness of 0.24 inches was found to be satisfactory.

TABLE II

SHREDDER PunCH HOLE TEST

\begin{tabular}{|l|l|l|}
\hline \multicolumn{1}{|c|}{ METAL THICKNESS (IN) } & \multicolumn{1}{|c|}{ PRE-DRILLED HOLE SIZE (IN) } & \multicolumn{1}{c|}{ DEFORMED HEIGHT (IN) } \\
\hline 0.021 Hot rolled steel (HRS) & $0.375(3 / 8)$ & 0.138 \\
\hline 0.021 HRS & $0.438(7 / 16)$ & 0.155 \\
\hline 0.021 HRS & $0.500(1 / 2)$ & 0.151 \\
\hline 0.024 HRS & $0.375(3 / 8)$ & Tore material \\
\hline 0.024 HRS & $0.438(7 / 16)$ & 0.160 \\
\hline 0.024 HRS & $0.500(1 / 2)$ & 0.100 \\
\hline 0.030 Stainless steel (SS) & $0.375(3 / 8)$ & 0.162 \\
\hline 0.030 SS & $0.438(7 / 16)$ & 0.150 \\
\hline 0.030 SS & $0.500(1 / 2)$ & 0.095 \\
\hline
\end{tabular}

The process for creating a shredder blade required that the corresponding hole pattern be drilled into the sheet metal first using a standard drill and bit. This was done by creating a hole template (Figure 10) to determine the location and spacing of the holes. The sheet metal was clamped between the hole template and a piece of wood so that the holes could be drilled through the template with a standard drill bit. The sheet metal was then placed on the die and the slicing profiles pounded into the sheet metal using the punch. The slicing profiles can be sharpened with a small round file. The Hobart blade has a raised lip around the outside that was used to stiffen the blade. The fabricated blade was found to be relatively stiff without the raised 
edge but deformed slightly from the fabrication process (Figure 11). In addition, the redesigned shredder mount holds the blade at four mounting holes whereas the previous mount only held the blade at two holes. Based on these two factors, it was determined that the raised lip was not needed on the fabricated blade.

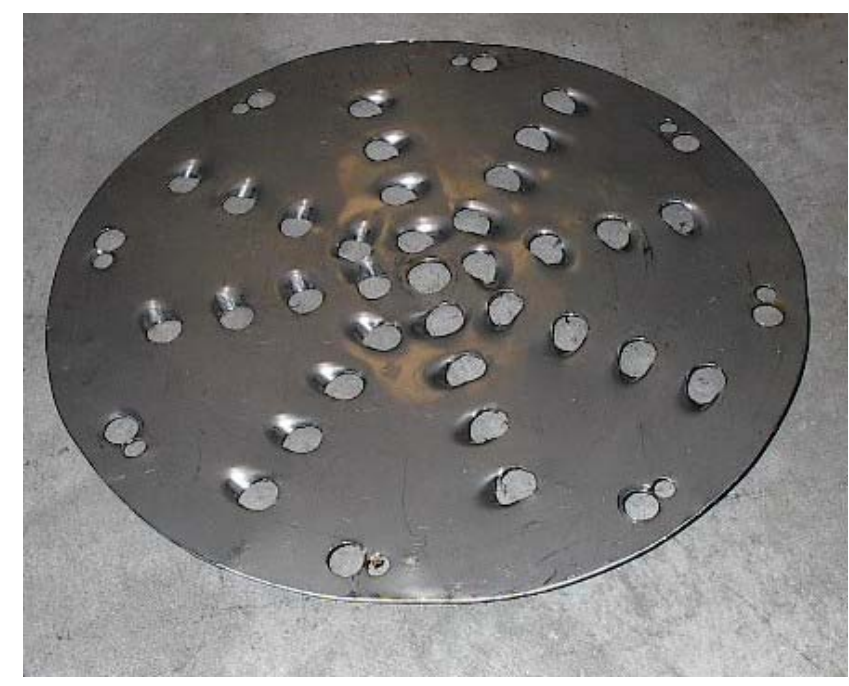

\section{FIGURE 11 \\ FABRICATED BLADE \\ REDESIGN RESULTS}

Redesigning the handle and crank assembly reduced the fabricated parts of this machine. A simple bent piece of round steel replaced the drive rod, handle crank, and handle post. The types of raw material needed were also reduced by eliminating the flat steel on the handle crank and changing the spacer for the feeder tube hoop from a steel block to the same tube material as the bearing supports.

Several of the purchased materials used in the original Tommy Shredder were potentially difficult to get in a developing country. This included the flat PVC plate used for the center divider and the oil-impregnated bronze bushings. These were replaced with more common materials such as sheet metal for the center divider and plastic or wood for the bushings. All of the work done to manufacture the shredder was done with tools that would typically be found in a small machine shop; a drill, saw, hammer, welder, and a lathe.

The final cost of the machine decreased as a result of this redesign. The elimination of the expensive flat PVC and less machining for the crank assemble offset the added materials cost for the sturdier blade support. By fabricating a shredding blade locally, the cost savings will be significant. It is estimated that it will take a person about half of a day to fabricate a shredding blade using the die, punch, and template described in the previous section. Using a labor rate of 8 dollars per day for a developing country and a material price of 4 dollars, the blade will cost about 8 dollars to make. This is a significant savings over the $\$ 27.00$ Hobart blade that would need to be specially ordered from outside the country.

The user satisfaction with the machine was increased in two ways. The sanitation and cleanliness of the shredder was greatly improved by making the center divider removable, allowing the feeder tube and divider to be cleaned separately. All pockets that could trap food 
were eliminated. The heavier blade support improves the quality of the device by making it more durable.

Table III shows a summary of changes that were made and the estimated cost associated with those parts. The labor rate used was 8 dollars a day. The cost shown is the sum of the labor rate and materials cost. The cost estimate was reduced by 31 dollars, which is a significant reduction in the total cost of the machine.

TABLE III

FABRICATION TIME AND COST OF THE PREVIOUS SHREDDER DESIGN AND THE NEW SHREDDER DESIGN

\begin{tabular}{|l|c|c|c|c|}
\hline Part & $\begin{array}{c}\text { Previous } \\
\text { Fabrication Time }\end{array}$ & $\begin{array}{c}\text { Previous Cost } \\
(\mathbf{\$})\end{array}$ & $\begin{array}{c}\text { New Fabrication } \\
\text { Time (Hrs) }\end{array}$ & New Cost (\$) \\
\hline Drive Shaft & 1.5 Hrs & 5 & 1 & 3 \\
\hline Drive Shaft Bushings & -- & 4 & 1 & 3 \\
\hline Frame Plate & 4 & 12 & 4 & 11 \\
\hline Center Divider & 1 & 16 & .5 & 4 \\
\hline Blade Mount & 3 & 8 & 4 & 8 \\
\hline Shredder Blade & -- & 27 & 4 & 41 \\
\hline $\begin{array}{l}\text { Cost of Modified } \\
\text { Parts }\end{array}$ & & 72 & & \\
\hline
\end{tabular}

The redesign process using the DFMA principles of manufacturing, made the breadfruit shredder more robust, and easier to manufacture in a developing country. There are multiple benefits of being able to manufacture a device locally. Local machine shops will benefit from the business, and repairs can be made nearby. The shredder will be manufactured and tested in the field during 2006.

\section{ACKNOWLEDGMENT}

The authors acknowledge Mr. Larry Mathews for his generous support of this project; the senior design work of Adam Spah, Michelle Anderson, Robert Fox and Ben Rick; the work of Hezbon Mose in making of the tool and die for the blade; and Karl Mueller for his manufacturing insights. 
i www.state.gov

ii CIA Fact Book, 2005

iii CIA Fact Book, 2005

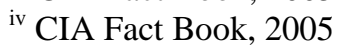

v Adebowale, K.O., Olu-Owolabi, B.I., Olawumi, E.K., \& Lawal, O.S. Functional Properties of Native, Physically and Chemically Modified Breadfruit (Artocarpus Artilis) Starch. Industrial Crops and Products, Vol. 21, Issue 3, May 2005, 343-351

${ }^{v i}$ www.breadfruit.org

vii Capecchi, C. Engineer Turns Wasted Fruit Into Hunger Fighter for Haiti. The Catholic Spirit, Vol. 10, No. 23, June 23, 2005.

viii Emiliusen J., Mauritzen T., McGruder, R., \& Torgerson, K. (2004). The Design of a Novel Breadfruit Dehydration System Utilizing Solar Energy: A Record of Year-Long Result. St. Paul: University of St. Thomas School of Engineering. http://courseweb.stthomas.edu/cmgeorge/breadfruit_dryer/

${ }^{\text {ix }}$ Garwick, Hank and Elton, Dave. Compatible Technology, International. Interview with author, May $26,2005$. Interview notes available.

${ }^{\mathrm{x}}$ Anderson, M. Fox, B., Rick, B., \& Spah, A. (2004). Design of a manually operated food shredder for the developing world. St. Paul. University of St. Thomas, School of engineering. http://courseweb.stthomas.edu/cmgeorge/breadfruit_shredder/

${ }^{\mathrm{xi}}$ Thilmany, J. (2005). Managing Across Cultures. ASME magazine, vol. 127/No. 2. February 2005, p 41-43.

xii El-Mously, Hamed. The Rediscovery of Local Raw Materials: New Opportunities for Developing Countries. Industry and Environment, Vol. 20, No. 1-2, Jan-Jun, 1997.

xiii Bruun, P., \& Medfford, R.N., A Framework for Selecting and Introducing Appropriate Production Technology in Developing Countries. International Journal of Production Economies, Vol. 46-47, December 1996, 197-209.

${ }^{\text {xiv }}$ Hynd, A., \& Smith, A. Meeting a Pressing Need: Project Appraisal of the Oilseed Ram Press and Approaches to Implementation. Design for Developing Countries Case Study Series, Issued October 20, 2004.

${ }^{\mathrm{xv}}$ Goldey, P., Thakur, S., \& Varma, S.K. (2001). Perceptions of Drudgery in Agricultural and Animal Husbandry Operations: A Gender Analysis From Haryana State, India. Journal of International Development, 1165-1178

${ }^{x v i}$ Obi, S. A Framework for Implementing Appropriate Manufacturing Systems in Developing Countries. Journal of Industrial Technology, Vol.15, No. 2, Feb. 1999.

${ }^{\text {xvii }}$ Humphrys, Bruce. Compatible Technology, International. Interview with author, December 28, 2004. Interview notes available.

xviii Garwick, Hank and Elton, Dave. Compatible Technology, International. Interview with author, May 26, 2005. Interview notes available.

${ }^{\text {xix }}$ Hegele, Fred. General Mills, Inc. Interview with author, April 18, 2005. Interview notes available.

${ }^{x x}$ Olmstead, Gary. General Mills, Inc. Interview with author, March 18, 2005. Interview notes available. 